\title{
Suppression of SCIN inhibits human prostate cancer cell proliferation and induces G0/G1 phase arrest
}

\author{
DONG WANG $^{1 *}$, SHU-QING SUN ${ }^{2 *}$, YING-HAO YU ${ }^{3}$, WEI-ZHEN WU ${ }^{1}$, \\ SHUN-LIANG YANG ${ }^{1}$ and JIAN-MING TAN ${ }^{1}$
}

Departments of ${ }^{1}$ Urology, ${ }^{2}$ Blood Purification and ${ }^{3}$ Pathology, Fuzhou General Hospital, Fuzhou 350025, P.R. China

Received August 8,2013; Accepted October 8, 2013

DOI: 10.3892/ijo.2013.2170

\begin{abstract}
SCIN is a calcium regulated actin severing and capping protein. Its homologue in zebrafish is found to be related with cell death. In the present study, we found that SCIN is highly expressed in human prostate cancer specimens. However, the functions of SCIN in human prostate carcinoma cells are largely unknown. To address the function of SCIN in prostate carcinoma cells, we used lentivirusmediated RNAi to knock down SCIN expression in PC3 cells, a prostate carcinoma cell line. We found that in vitro silencing of SCIN could inhibit the proliferation and colony formation ability of PC3 cells. Furthermore, cell cycle analysis showed that reduced SCIN expression lead to G0/G1 cell cycle arrest through the regulation of cell cycle-related genes, such as p21 Waf1/Cip1 , cyclin-dependent kinase inhibitor $2 \mathrm{~A}$ (CDKN2A, p16 ${ }^{\text {Ink4A }}$ ) and cyclin A2. These results suggest that SCIN plays an important role in the proliferation of prostate cancer cells and lentivirus-mediated inhibition of SCIN expression may be a potential therapeutic method for the treatment of prostate cancer.
\end{abstract}

\section{Introduction}

Prostate cancer is one of the most frequently diagnosed non-cutaneous malignancies and the sixth leading cause of cancer death in males, accounting for $14 \%(903,500)$ of the total new cancer cases and $6 \%(258,400)$ of the total cancer deaths in males, in 2008 (1). Incidence and mortality rates are rising in Asian countries. Older age, race and family history remain the only well-established risk factors and there are no established preventable risk factors for prostate cancer (2). Mutations of tumor suppressor genes in individuals suffering from prostate cancer may lead its specificity among selected

Correspondence to: Professor Dong Wang or Professor Jian-Ming Tan, Department of Urology, Fuzhou General Hospital, 156, Xi'erhuan North Road, Fuzhou 350025, P.R. China

E-mail: dongwangdr@163.com

E-mail: tanjm156@gmail.com

*Contributed equally

Key words: SCIN, adseverin, lentivirus, RNAi, prostate cancer group of individuals. For example, it has been found that putative tumor suppressor gene (PTEN/MMAC1) on 10q23 is one of the most frequently deleted chromosomal regions in human prostate cancer $(3,4)$. Therefore, genome-based therapies are potentially ideal options for prostate cancer therapy.

Cytoskeleton plays essential roles in the mitosis, migration and invasion of carcinoma cells (5). Many cytoskeletonassociated proteins of prostate cancer cells have been intensively investigated (6-10). SCIN is a calcium dependent actin filament serving and capping protein (11). It could regulate vesicle transport and exocytosis by organizing the cytoskeleton underneath the plasma membrane $(12,13)$. It also regulated cell differentiation through the MAP kinases P38 and ERK1/2 mediated signaling pathway (14). The reduction in expression of Scinlb, the homolog of SCIN in zebrafish, was found to be associated with increased cell death (15). Previous studies have found SCIN is abnormal in certain kind of carcinomas and revealed that SCIN is involved in many processes of carcinoma cells, such as proliferation and tumor resistance. In the megakaryoblastic leukemia cell lines, SCIN is downregulated and overexpression of SCIN in these cells inhibited proliferation and tumorigenesis (16). In the T cell lysis resistant tumor cells, SCIN is overexpressed and the knockdown of SCIN significantly attenuated the resistance to cytolytic T lymphocytes killing (17). However, the function of SCIN in prostate cancer is largely unknown.

In the present study, we found that SCIN is overexpressed in prostate cancer specimens. To investigate the physiological function of SCIN in prostate cancer, we took advantage of lentivirus-mediated RNAi to suppress the expression of SCIN in the prostate cancer PC3 cells. We found that SCIN suppression reduced the proliferation and colony formation ability of prostate cancer cells. Furthermore, SCIN silencing was associated with G0/G1 cell cycle arrest. After SCIN silencing, the expression of p21 and p16 was significantly increased and the expression of cyclin A2 was reduced. Taken together, our study indicates that SCIN is essential for the proliferation of prostate cancer and lentivirus mediated SCIN silencing is a promising therapeutic method for the treatment of prostate cancer.

\section{Materials and methods}

Immunohistochemistry. Tumor specimens from 193 patients who underwent surgery for primary breast cancer from 2008 
to 2012 at Fuzhou General Hospital (Fuzhou, China), were evaluated in this study. The samples were used with the written informed consent from patient and the approval of the ethics committee of Fuzhou General Hospital. The mean age of the patients at the time of surgery was 71.1 years. All tumors were from patients with newly diagnosed prostate cancer who had received no therapy before sample collection.

Immunoperoxidase staining was performed on $2 \mu \mathrm{m}$ paraffin sections. All sections were treated with $0.3 \% \mathrm{H}_{2} \mathrm{O}_{2}$ to exhaust endogenous peroxidase activity. Avidin/biotin blocking solutions were used to prevent the non-specific binding of possible endogenous biotin- or avidin-binding proteins. Blocking with $10 \%$ normal goat serum was performed before applying the primary antibody against SCIN (1:150, Cat\# HPA024264, Sigma-Aldrich). Biotinylated goat anti-rabbit IgG was used as the secondary antibody. The immunoreactions were detected by staining with 3,3'-diaminobenzidine (DAB). For all cases, representative pictures (x20 magnification) of selected regions in the SCIN-positive sections were taken with a microscope. Negative controls were performed by omitting the primary antibody.

The slides were evaluated in a double-blinded manner by three pathologists independently, and the scores were supplied by the proportion of positive tumor cells and the intensity of the coloring. The result of the tissues was determined from at least 1,000 cells that were counted systematically at x400 magnification in ten visual fields selected at random. The proportion of positive tumor cells were recorded according to the following classification: 0 , no cells stained; $1,<1 / 3$ of cells stained; $2,1 / 3-2 / 3$ of cells stained and $3,>2 / 3$ of cells stained. However, the groups could also be classified into the following 4 groups by the intensity of the coloring: 0 , no coloring; 1 , stramineous; 2 , buffy; and 3, dark brown. The two scores were combined to obtain the final one: scores equal to 0 indicate negative (-), whereas scores from 2 to 3 indicate weakly positive $(+), 4$ indicate positive $(++)$, and 5 to 6 indicate strongly-positive $(+++)$.

Cell culture. Human prostate cancer PC3 cells and human embryonic kidney HEK293T cells are provided by the Cell Bank of Chinese Academy of Sciences (Shanghai, China). PC3 and HEK293T cells were maintained in DMEM medium (HyClone) supplemented with $10 \%$ fetal bovine serum (FBS), L-glutamine, penicillin and streptomycin at $37^{\circ} \mathrm{C}$ in a humidified $5 \% \mathrm{CO}_{2}$ atmosphere.

Construction of SCIN shRNA plasmid. A 67 bp shRNA targeted SCIN (NM_033128) was designed (5'-CTAGCCG GGCAAGTGTCCTAAAGTGCAAATTCAAGAGATTTGC ACTTTAGGACACTTGCTTTTTAAT-3'). Another 67 bp random shRNA (5'-CTAGCCCGGTTCTCCGAACGTGTCA CGTATCTCGAGATACGTGA CACGTT CGGAGAATTTTT TTAAT-3') was used as negative control. Both shRNA were liagated into lentiviral pFH-L plasmid (Shanghai Hollybio, Shanghai, China).

Lentivirus packaging and infection. For lentivirus packaging, HEK 293T cells were transfected with pFH-L-SCIN shRNA or control shRNA together with two helper plasmids (pVSVG-I and $\mathrm{pCMV} \Delta \mathrm{R} 8.92$, Shanghai Hollybio) using Lipfectamine 2000 (Invitrogen) according to the manufacturer's instruc- tions. Two days after transfection, supernatant containing packaged lentivirus was collected and passed through $0.45 \mu \mathrm{m}$ filters. To infect PC3 cells, lentivirus particles were added to the culture medium at a MOI of 50. Cells were then cultured in the incubator at $37^{\circ} \mathrm{C}$.

RNA extraction and real-time PCR (RT-PCR). After lentivirus infection, PC3 cells were washed by PBS and collected. Total RNA was extracted using TRIzol reagent (Invitrogen). cDNA was then retro-transcribed with oligo dT using M-MLV reverse transcriptase (Promega). The expression level of SCIN was measured by RT-PCR with primers: forward, 5'-ATTGTGGA GGTTGATGTTGATG-3'; and reverse, 5'-AGTGGTGAGGTC TGGTAGTC-3'. The primers of actin, used as endogenous control, are: forward, 5'-GTGGACATCCGCAAAGAC-3' and reverse 5'-AAAGGGTGTAACGCAACTA-3'. The PCR reaction system was $10 \mu \mathrm{l} 2 \mathrm{X}$ SYBR premix ex-taq, $0.8 \mu 1$ primers $(2.5 \mu \mathrm{M}), 5 \mu \mathrm{l}$ cDNA and $\mathrm{ddH}_{2} \mathrm{O}$ up to final $20 \mu \mathrm{l}$ volume. Probe amplification was performed as follows: $1 \mathrm{~min}$ at $95^{\circ} \mathrm{C}$; 40 cycles of $95^{\circ} \mathrm{C}$ for $5 \mathrm{sec}$ and at $60^{\circ} \mathrm{C}$ for $20 \mathrm{sec}$. The expression level of SCIN was determined by cycle threshold $(\mathrm{Ct})$ normalized with that of actin using $2^{-\Delta \Delta C t}$ formula. All experiments were repeated at least three times.

Western blot analysis. Lentivirus-transduced cells were washed twice with ice-cold PBS and suspended in a lysis buffer (2\% mercaptoethanol, 20\% glycerol, 4\% SDS in $100 \mathrm{mM}$ Tris- $\mathrm{HCl}$ buffer, $\mathrm{pH}$ 6.8). After $15 \mathrm{~min}$ of incubation on ice, cells were disrupted by ultrasound on ice. Total cell lysates were then centrifuged $\left(12,000 \mathrm{x} \mathrm{g}, 15 \mathrm{~min}, 4^{\circ} \mathrm{C}\right)$ and the supernatants were employed for further processing. The protein concentration was determined by using the BCA protein assay kit. Equal amount of proteins was loaded and separated by SDS-PAGE, and was then transferred onto PVDF membrane (Schleicher \& Schuell Co., Keene, NH) using an electro-blotting apparatus (Tanon, Shanghai, China). The membrane was blocked with $5 \%$ non-fat milk in TBST solution for $1 \mathrm{~h}$ at room temperature, and incubated overnight at $4^{\circ} \mathrm{C}$ with specific antibody tocsin at a dilution 1:1,500. After the three washes with TBST solution, the membrane was incubated with horseradish peroxidase-conjugated secondary antibody diluted with TBST solution at room temperature for $2 \mathrm{~h}$. The signals of detected proteins were visualized on ECL plus Western blotting detection system (Amersham Biosciences Inc., Piscataway, NJ). GAPDH protein levels were used as a loading control.

MTT assay. PC3 cells were seeded into a 96-well plate at an initial concentration of 2,000 cells/well and proceeded to MTT assay according to the manual. In brief, MTT solution was added to wells and incubated at $37^{\circ} \mathrm{C}$ for $4 \mathrm{~h}$ at different time points after lentivirus infection (1, 2, 3, 4, 5 days). Then the converted dye solubilized in acidic isopropanol (10\% SDS, $5 \%$ isopropanol and $0.01 \mathrm{M} \mathrm{HCl}$ ) was used and incubated at $37^{\circ} \mathrm{C}$ for $10 \mathrm{~min}$. The optical density was measured using microplate reader at the wavelength of $595 \mathrm{~nm}$. The experiment was repeated at least three times.

BrdU incorporation assay. Cell proliferation was also quantified by measuring BrdU incorporation during DNA synthesis 
Table I. Expression pattern of SCIN in prostate cancer tissues with a different degree of differentiation.

\begin{tabular}{lcccccr}
\hline & & \multicolumn{5}{c}{ SCIN expression } \\
\cline { 3 - 7 } Type of tissues & $\begin{array}{c}\text { No. of } \\
\text { cases }\end{array}$ & $\begin{array}{c}\text { Negative } \\
(-)\end{array}$ & $\begin{array}{c}\text { Weakly positive } \\
(+)\end{array}$ & $\begin{array}{c}\text { Positive } \\
(++)\end{array}$ & $\begin{array}{c}\text { Strongly-positive } \\
(+++)\end{array}$ & P-value \\
\hline Well-differentiated & 10 & 4 & 2 & 4 & 0 & $0.0004^{*}$ \\
Moderately differentiated & 89 & 6 & 32 & 47 & 4 & 5 \\
Poorly differentiated & 74 & 5 & 10 & 54 & 5 \\
\hline
\end{tabular}

${ }^{*} \mathrm{P}<0.05, \chi^{2}$ test.

using the BrdU Cell Proliferation ELISA kit. The experiment was performed according to the manufacturer's protocol. Briefly, $10 \mu \mathrm{l} /$ well of BrdU labeling solution was added to cells at 24 or $72 \mathrm{~h}$ after culture. After overnight incubation, cells were fixed with $200 \mu \mathrm{l} /$ well of fix solution for $30 \mathrm{~min}$ in the dark at room temperature, and then incubated with peroxidase-conjugated anti-BrdU antibody for $90 \mathrm{~min}$. A substrate solution was then added into each well, and absorbance was measured using a microplate reader (Bio-Rad 680) at a wavelength of $450 \mathrm{~nm}$ with a reference wavelength of $630 \mathrm{~nm}$. The number of proliferating cells is represented by the level of BrdU incorporation which directly correlates to the absorbance values. Growth rate $(\mathrm{R})$ was calculated by the following equation: $R=\left(A_{72 h}-A_{24 h}\right) / A_{24 h} \times 100$, where $A_{72 h}$ and $\mathrm{A}_{24 \mathrm{~h}}$ indicate the absorbance at $450 \mathrm{~nm}$ after 24 and $72 \mathrm{~h}$ of incubation.

Colony formation assay. Colony formation assay was performed according to the literature (18). In brief, three days after lentivirus infection, about 200 cells of PC3 cells were seeded into each well of a 6-well plate. Cells were cultured in the $37^{\circ} \mathrm{C}$ incubator for about 9 days until most single clones had more than 50 cells. Cells were washed by PBS and fixed by $4 \%$ PFA. Then, Giemsa staining was performed and images were captured by a fluorescence microscope. The experiments were performed at least three times.

Flow cytometry analysis. Cell cycle of PC3 cells was analyzed by flow cytometry. In brief, four days after lentivirus infection, PC3 cells were collected, washed by PBS and fixed by $75 \%$ ethanol. Cells were stained with propidium iodide (PI) and RNase overnight at $4^{\circ} \mathrm{C}$. Samples were then analyzed by Cell Lab Quanta Beckman Coulter. The experiment was repeated at least three times.

Statistical analysis. The results of immunohistochemistry staining were evaluated by $\chi^{2}$ test and the other data were evaluated by Student's t-test and expressed as the mean \pm SD. Statistical analyses were performed using GraphPad Prism 5 and $\mathrm{P}<0.05$ was considered to be statistically significant.

\section{Results}

SCIN is highly expressed in prostate cancer. Previous studies indicate that the expression of SCIN is changed in certain carcinoma cells $(17,19,20)$. To investigate the function of SCIN in prostate cancer, we evaluated the protein level in 173 prostate cancer specimens using immunohistochemical staining. Of the 173 prostate cancer samples, $9(5.2 \%)$ are strongly-positive, $106(60.7 \%)$ are positive and 44 (25.4) are weak positive. Representative immunohistochemical staining is shown in Fig. 1, and the entire dataset is illustrated in Table I. These results suggest that the high expression level of SCIN in prostate cancer may be involved in the pathogenesis of prostate cancers. Previous studies suggest that prostate cancer is associated with age and gender of patients $(21,22)$. To investigate the association of SCIN expression with these two factors, we analyzed the SCIN expression level in prostate cancer tissues with different factors. We found that SCIN expression level is not associated with gender and age (data not shown). We also determined the relationship between the immunohistochemical expression level of SCIN and the degree of differentiation of cancers. We found that SCIN protein is related to the degree of differentiation of prostate malignancy (Table I, $\mathrm{p}<0.05, \chi^{2}$ test).

Lentivirus-mediated RNAi efficiently knocks down endogenous SCIN expression in PC3 cells. To investigate the physiological function of SCIN in prostate cancer cells, we took advantage of lentivirus-mediated RNAi technology, a powerful method to knock down the endogenous gene expression in vivo. Five days after lentivirus infection, GFP fluorescence showed high percentage of PC3 cells being infected by lentivirus (Fig. 2A). Furthermore, using RT-PCR and western blot analysis, we found that after si-SCIN infection, the mRNA level of SCIN was significantly reduced compared with the si-CTRL infected group (Fig. 2B and C). These results suggest that lentivirus-mediated RNAi was able to significantly knock down the endogenous SCIN expression in PC3 cells.

SCIN silencing reduces the proliferation and colony formation ability of PC3 cells. Using MTT assay, we examined the impact of SCIN silencing on the proliferation ability of PC3 cells. We found that after si-SCIN infection, cell growth was dramatically reduced compared with the si-CTRL infected PC3 cells (Fig. 3A). Cell proliferative activity was then assessed by BrdU incorporation into cellular DNA. Fig. 3B shows a significant decrease in DNA synthesis as demonstrated by decreased BrdU incorporation in the si-SCIN 

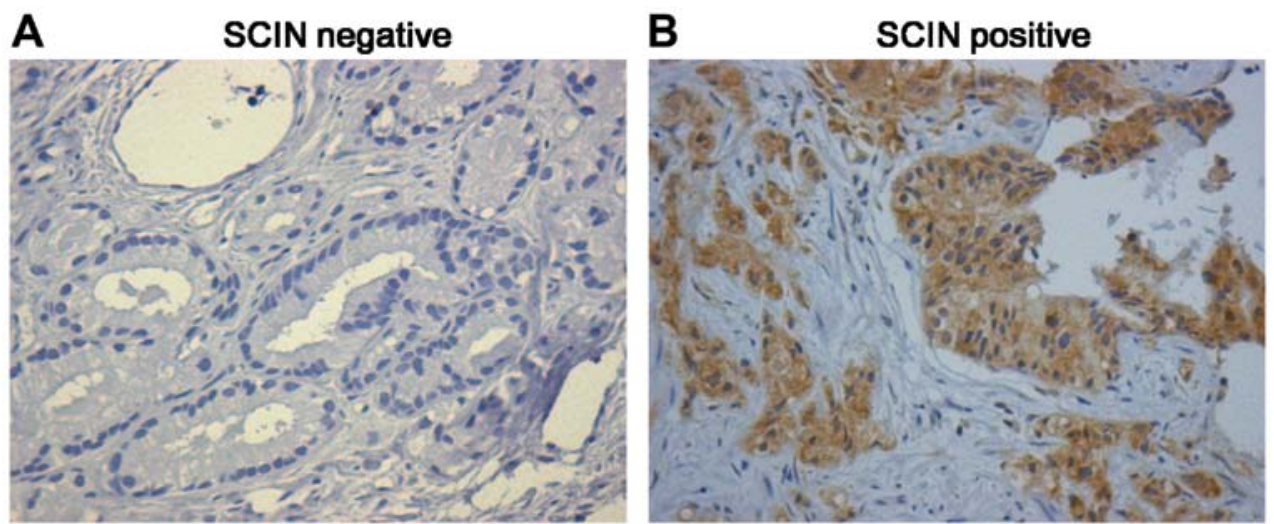

Figure 1. Immunohistochemical analysis of SCIN expression in human prostate cancer and adjacent normal tissue. (A) Negative and (B) positive SCIN staining. Original magnification, $\mathrm{x} 20$ objective lens.
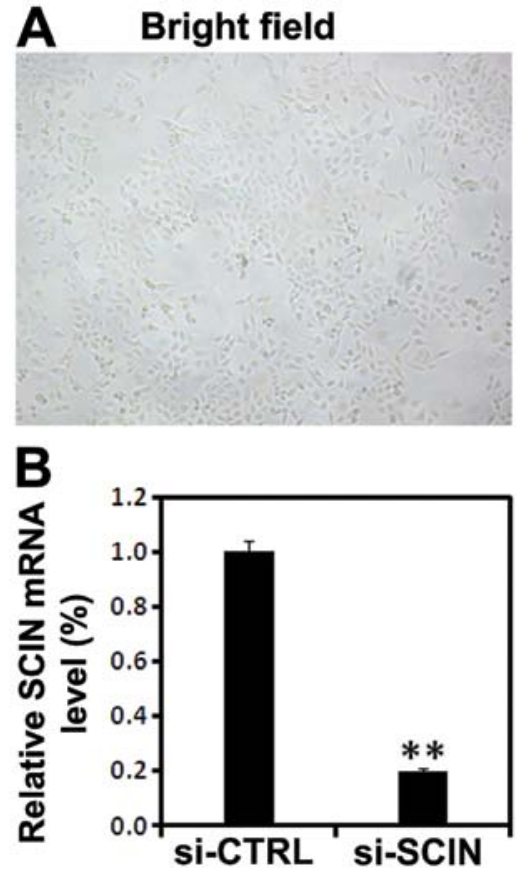

Fluorescent field

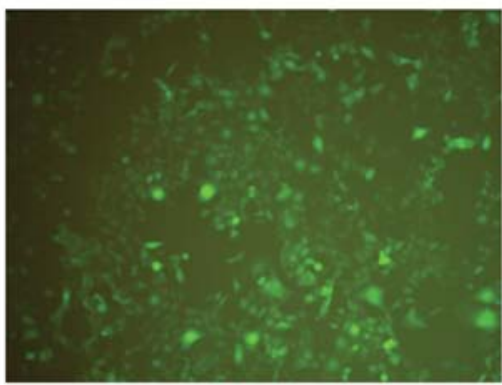

C

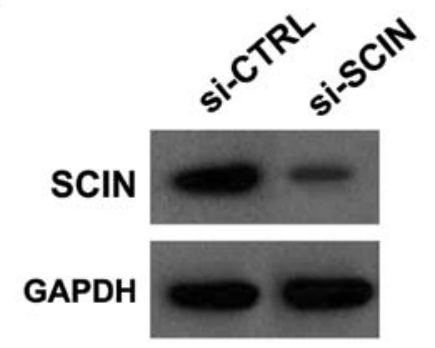

Figure 2. Lentivirus-mediated siRNA decreases SCIN expression in PC3 cells. The lentivirus transduction efficiency was estimated 3 days after infection at MOI of 50. GFP expression in transfected cells was observed under light a microscope and a fluorescence microscope. Light micrograph (left panel); fluorescent micrograph (right panel; x100). (B) Total RNA was extracted at 5 days after infection and relative SCIN mRNA expression was determined by quantitative real-time RT-PCR $\beta$-actin was used to an internal gene. Data represent the mean $\pm \mathrm{SD}$ of three independent experiments. ${ }^{* * *} \mathrm{P}<0.01$, compared with si-CTRL. (C) Total cellular proteins were extracted 5 days after infection and determined by western blot analysis using antibodies against SCIN and GAPDH as an internal control. Data represent one out of three separate experiments. si-CTRL, cells transduced with lentivirus-mediated scr-siRNA; si-SCIN, cells transduced with lentivirus-mediated SCIN-siRNA.

group in comparison to si-CTRL after $72 \mathrm{~h}$ of lentivirus transduction $\left({ }^{* *} \mathrm{P}<0.01\right)$. Furthermore, we found the colony numbers were reduced in si-SCIN infected PC3 (Fig. 3C and D) cells. In summary, SCIN silencing was able to inhibit the proliferation and colony formation ability of prostate cancer cells.

SCIN silencing leads to G0/G1 cell cycle arrest. To investigate the inhibition of the mechanisms of SCIN silencing induced cell proliferation, flow cytometry analysis of cell cycle was performed. We found that after si-SCIN infection, $73 \%$ of PC 3 cells are in the G0/G1 phase and $4 \%$ are in the
$\mathrm{S}$ phase of the cell cycle, while $64 \%$ of si-CTRL infected cells are in the G0/G1 and $18 \%$ are in the $S$ phase of the cell cycle (Fig. 4A and B). Furthermore, to obtain mechanistic insight into a role for SCIN in cell cycle arrest, we performed real-time RT-PCR analysis to assess the mRNA level of cell cycle-related molecules. After 3 days of transduction, RNAi-mediated SCIN silencing induced upregulation of p2 $1^{\text {waf1/cip1 }}$ and p16 and downregulation of cyclin A2 in PC3 cells (Fig. 4C). The results demonstrated that SCIN may be involved in regulating the cyclins-cyclin-dependent kinases (CDKs)-CDK inhibitor (CDKI) expression in PC3 cells. 

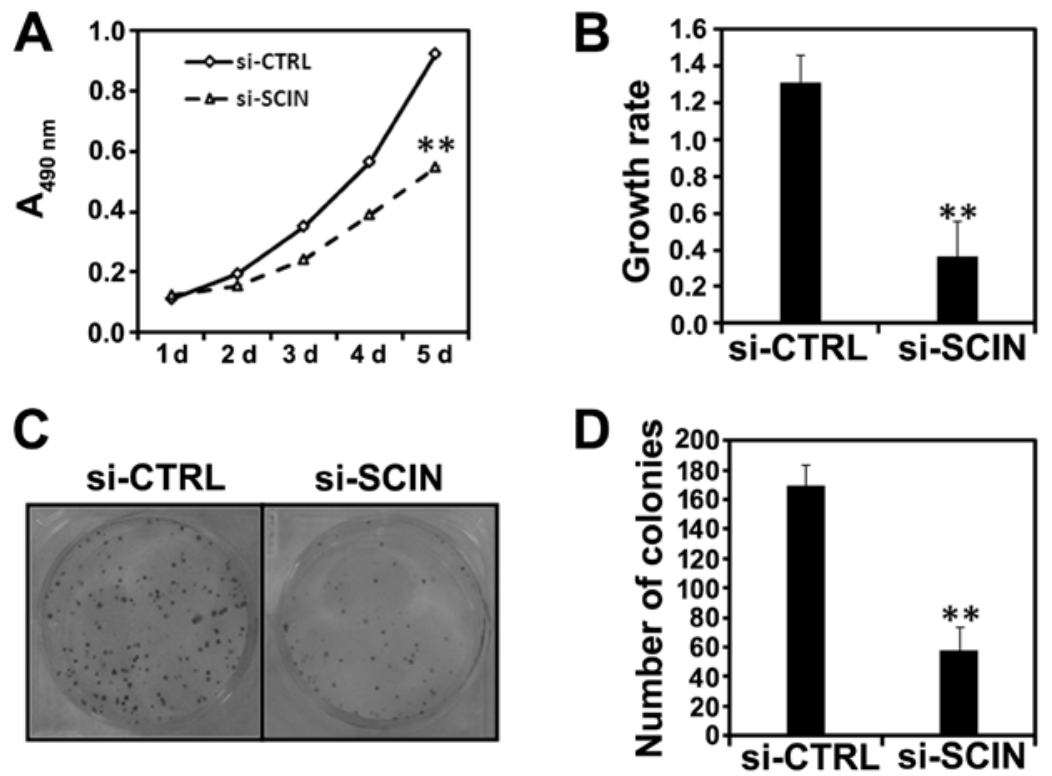

Figure 3. Lentivirus-mediated siRNA targeting SCIN inhibited PC3 cell proliferation. (A) Cell proliferation of untranfected or transfected PC3 cells was measured by MTT assay once daily for 5 days. (B) DNA synthesis was measured by BrdU incorporation assay at 24 and $72 \mathrm{~h}$ after transduction. Growth rate (R) was calculated by the following equation to reflect the role of SCIN in DNA synthesis ability: $R=\left(\mathrm{A}_{72 \mathrm{~h}}-\mathrm{A}_{24 \mathrm{~h}}\right) / \mathrm{A}_{24 \mathrm{~h}} \mathrm{x} 100$, where $\mathrm{A}_{72 \mathrm{~h}}$ and $\mathrm{A}_{24 \mathrm{~h}}$ indicate the absorbance at $450 \mathrm{~nm}$ after 24 and $72 \mathrm{~h}$ of incubation. (C and D) PC 3 cells were seeded at 200 per well and allowed to form colonies. Colony numbers were counted and recorded. The colonies stained with Giemsa were observed under light microscopy. Data represent the mean \pm SD of three independent experiments. ${ }^{* *} \mathrm{P}<0.01$, compared with si-CTRL.
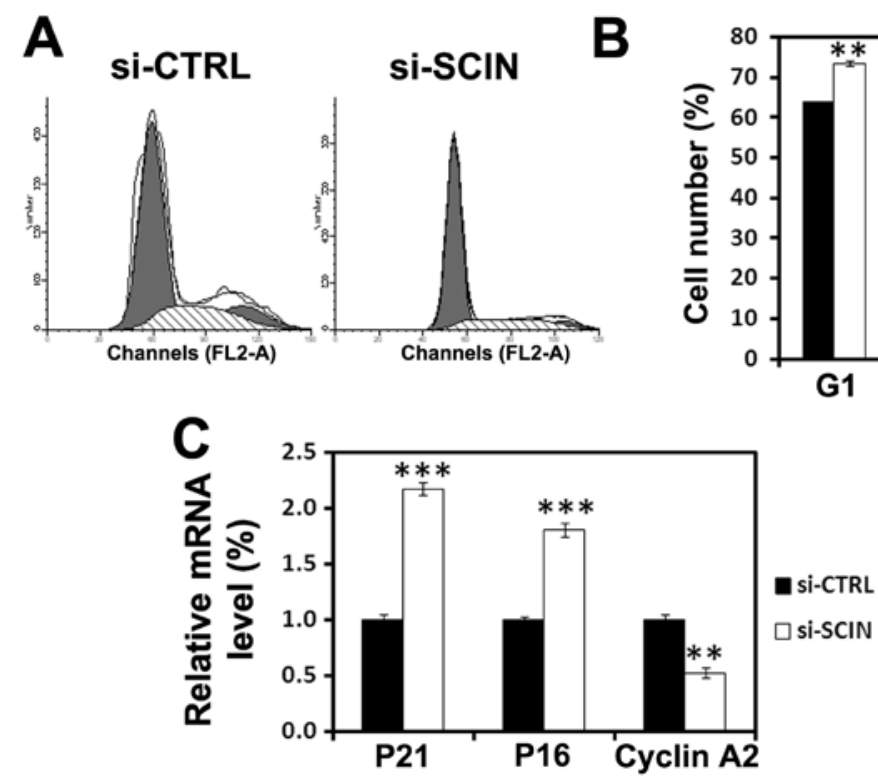

Figure 4. Flow cytometric analysis of cell cycle distribution. (A and B) Knockdown of SCIN by RNAi in PC 3 cells induced cell cycle arrest in G0/G1 phase 5 days after lentivirus transduction. Data represent the mean $\pm \mathrm{SD}$ of three independent experiments. ${ }^{* * *} \mathrm{P}<0.01$, compared with si-CTRL. si-CTRL, cells transduced with lentivirus-mediated scr-siRNA; si-SCIN, cells transduced with lentivirus-mediated SCIN-siRNA. (C) Effect of SCIN knockdown on cell cycle regulators. Total RNA was extracted at 5 days after infection and relative p21, p16 an cyclin A2 mRNA expression was determined by quantitative real-time RT-PCR. $\beta$-actin was used as an internal gene. Data represent the mean $\pm \mathrm{SD}$ of three independent experiments. ${ }^{* *} \mathrm{P}<0.01,{ }^{* * *} \mathrm{P}<0.001$, compared with si-CTRL.

\section{Discussion}

Prostate cancer is one of the most common causes of cancer-related death. Based on the cell types, prostate cancer could be classified to two main types, small cell prostate cancer and non-small cell prostate cancer. Different therapeutic methods have been used clinically for the treatment of pros- tate cancer, including palliative care, surgery, chemotherapy and radiation therapy. However, only $15 \%$ survive for five years after diagnosis $(23,24)$. New therapeutic gene targets and methods are needed. Lentivirus mediated gene silencing could specifically suppress target genes in vivo. The specificity, higher infection rate and stability of this method gives it high potential as a therapeutic method for treatment of 
cancer. In the present study, using this method, we specifically suppress endogenous SCIN expression in prostate cancer cell lines and significantly inhibit the proliferation of PC3 cells.

In carcinoma cells, the cytoskeleton is abnormal and the expression of some cytoskeleton-associated proteins is aberrant (6). In the present study, we found that SCIN is highly expressed in the prostate cancer samples and about $7 \%$ prostate cancer samples have aberrantly strong SCIN expression. A previous study found that $\mathrm{T}$ cell lysis resistant tumor cells have aberrant strong SCIN expression and the knockdown of SCIN significantly attenuated the resistance to cytolytic $\mathrm{T}$ lymphocytes killing. Knockdown of SCIN expression in vivo may facilitate prostate cancer cells being killed by $\mathrm{T}$ lymphocytes. Thus, lentivirus-mediated SCIN silencing in vivo, could have stronger effects.

Deregulated cell cycle progression is one of the primary characteristics of cancer cells (25). Cell cycle progression involves sequential activation of $\mathrm{CDK}$ s whose association with corresponding regulatory cyclins is necessary for their activation $(26,27)$. Cyclin-dependent kinase inhibitor 2A (CDKN2A, p16 ${ }^{\text {Ink4A }}$ ) also known as multiple tumor suppressor-1 (MTS-1), is a tumor suppressor protein, that in humans is encoded by the CDKN2A gene. P16 plays an important role in regulating the cell cycle, and mutations in p16 increase the risk of developing a variety of cancers. p21 is a potent cyclin-dependent kinase inhibitor (CKI). The p21 (CIP1/WAF1) protein binds to and inhibits the activity of cyclin-CDK2 or -CDK1 complexes, and thus functions as a regulator of cell cycle progression at G1. The protein encoded by cyclin A2 binds and activates CDC2 or CDK 2 kinases, and thus promotes both cell cycle G1/S and $\mathrm{G} 2 / \mathrm{M}$ transitions. In the present study SCIN silencing caused a marked increase in expression of p16 and p21 $1^{\text {waf } 1 / \text { cip } 1}$ and decreased expression of cyclin A2 in PC3 cells. These observations suggest that SCIN may play an important role in cell cycle progression of human prostate cancer by regulating the cyclins-CDKs-CDKI expression.

In conclusion, our results suggest that SCIN silencing by lentivirus-mediated RNAi was able to reduce the proliferation and colony formation ability of prostate cancer cells, possibly due to the cell cycle arrest at G0/G1 phase. Our studies provide a potential therapeutic gene target for the treatment of prostate cancer.

\section{Acknowledgements}

This study was supported by grants from the National Natural Science Foundation of China (81272247).

\section{References}

1. Jemal A, Bray F, Center MM, Ferlay J, Ward E and Forman D: Global cancer statistics. CA Cancer J Clin 61: 69-90, 2011.

2. Gronberg H: Prostate cancer epidemiology. Lancet 361: 859-864, 2003.

3. Dong JT, Li CL, Sipe TW and Frierson HF Jr: Mutations of PTEN/MMAC1 in primary prostate cancers from Chinese patients. Clin Cancer Res 7: 304-308, 2001.

4. Li J, Yen C, Liaw D, et al: PTEN, a putative protein tyrosine phosphatase gene mutated in human brain, breast, and prostate cancer. Science 275: 1943-1947, 1997.

5. Hall A: The cytoskeleton and cancer. Cancer Metastasis Rev 28: 5-14, 2009.
6. Bernal SD, Baylin SB, Shaper JH, Gazdar AF and Chen LB: Cytoskeleton-associated proteins of human lung cancer cells. Cancer Res 43: 1798-1808, 1983.

7. Chang WT, You BJ, Yang WH, Wu CY, Bau DT and Lee HZ: Protein kinase $\mathrm{C}$ delta-mediated cytoskeleton remodeling is involved in aloe-emodin-induced photokilling of human lung cancer cells. Anticancer Res 32: 3707-3713, 2012.

8. Niu J, Mo Q, Wang H, Li M, Cui J and Li Z: Invasion inhibition by a MEK inhibitor correlates with the actin-based cytoskeleton in lung cancer A549 cells. Biochem Biophys Res Commun 422: 80-84, 2012.

9. Chen QY, Xu LQ, Jiao DM, et al: Silencing of Rac1 modifies lung cancer cell migration, invasion and actin cytoskeleton rearrangements and enhances chemosensitivity to antitumor drugs. Int J Mol Med 28: 769-776, 2011.

10. Chen CH, Lin H, Chuang SM, Lin SY and Chen JJ: Acidic stress facilitates tyrosine phosphorylation of HLJ1 to associate with actin cytoskeleton in lung cancer cells. Exp Cell Res 316: 2910-2921, 2010.

11. Marcu MG,Zhang L, Elzagallaai A and Trifaro JM: Localization by segmental deletion analysis and functional characterization of a third actin-binding site in domain 5 of scinderin. J Biol Chem 273: 3661-3668, 1998.

12. Dumitrescu Pene T, Rose SD, Lejen T, Marcu MG and Trifaro JM: Expression of various scinderin domains in chromaffin cells indicates that this protein acts as a molecular switch in the control of actin filament dynamics and exocytosis. J Neurochem 92: 780-789, 2005.

13. Trifaro JM, Gasman S and Gutierrez LM: Cytoskeletal control of vesicle transport and exocytosis in chromaffin cells. Acta Physiol (Oxf) 192: 165-172, 2008.

14. Nurminsky D, Magee C, Faverman L and Nurminskaya M: Regulation of chondrocyte differentiation by actin-severing protein adseverin. Dev Biol 302: 427-437, 2007.

15. Jia S, Nakaya N and Piatigorsky J: Differential expression patterns and developmental roles of duplicated scinderin-like genes in zebrafish. Dev Dyn 238: 2633-2640, 2009.

16. Zunino R, Li Q, Rose SD, et al: Expression of scinderin in megakaryoblastic leukemia cells induces differentiation, maturation, and apoptosis with release of plateletlike particles and inhibits proliferation and tumorigenesis. Blood 98: 2210-2219, 2001.

17. Abouzahr S, Bismuth G, Gaudin C, et al: Identification of target actin content and polymerization status as a mechanism of tumor resistance after cytolytic T lymphocyte pressure. Proc Natl Acad Sci USA 103: 1428-1433, 2006.

18. Franken NA, Rodermond HM, Stap J, Haveman J and van Bree C: Clonogenic assay of cells in vitro. Nat Protoc 1: 2315-2319, 2006

19. Thorsen K, Schepeler T, Oster B, et al: Tumor-specific usage of alternative transcription start sites in colorectal cancer identified by genome-wide exon array analysis. BMC Genomics 12: $505,2011$.

20. Miura N, Takemori N, Kikugawa T, Tanji N, Higashiyama S and Yokoyama M: Adseverin: a novel cisplatin-resistant marker in the human bladder cancer cell line HT1376 identified by quantitative proteomic analysis. Mol Oncol 6: 311-322, 2012.

21. Harichand-Herdt S and Ramalingam SS: Gender-associated differences in lung cancer: clinical characteristics and treatment outcomes in women. Semin Oncol 36: 572-580, 2009.

22. Cepeda OA and Gammack JK: Cancer in older men: a genderbased review. Aging Male 9: 149-158, 2006.

23. Reddy C, Chilla D and Boltax J: Lung cancer screening: a review of available data and current guidelines. Hosp Pract (Minneap) 39: 107-112, 2011.

24. Bach PB, Mirkin JN, Oliver TK, et al: Benefits and harms of CT screening for lung cancer: a systematic review. JAMA 307: 2418-2429, 2012.

25. Grana $X$ and Reddy EP: Cell cycle control in mammalian cells: role of cyclins, cyclin dependent kinases (CDKs), growth suppressor genes and cyclin-dependent kinase inhibitors (CKIs). Oncogene 11: 211-219, 1995.

26. Schafer KA: The cell cycle: a review. Vet Pathol 35: 461-478, 1998.

27. Molinari M: Cell cycle checkpoints and their inactivation in human cancer. Cell Prolif 33: 261-274, 2000. 